\title{
TIỀM NĂNG NGÀNH DU LỊCH VIỆT NAM VÀ PHƯƠNG HƯỚNG PHÁT TRIỂN DU LỊCH SAU DỊCH BỆNH COVID - 19
}

\author{
Đinh Thị Tuyết, Nguyễn Thị Thu Thủy, Đỗ Văn Phúc \\ Trần Việt Hoàng, Nguyễn Thị Thanh Nhàn \\ Trường Đại học Quốc gia Hà Nội
}

Hà Nội, ngày 11/12/2021

Preprint DOI: https://osf.io/agr8c

Du lịch là một ngành kinh tế tổng hợp, có vị trí quan trọng đối với phát triển kinh tế, chính trị, xã hội và bảo vệ tài nguyên môi trường. Phát triển ngành du lịch sẽ góp phần vào chuyển dịch cơ cấu kinh tế, mang lại nguồn thu ngân sách quốc gia, thu hút vốn đầu tư và xuất khẩu hàng hóa tại chỗ, tác động tích cực đối với phát triển các ngành kinh tế có liên quan (Giang, 2021).

Trong những năm gần đây, ngành Du lịch Việt Nam đã có nhiều đổi mới và ngày càng được biết đến nhiều hơn trên thế giới, nhiều điểm đến trong nước được bình chọn là địa chỉ yêu thích của du khách quốc tế. Qua đó có thể thấy rõ tiềm năng để phát triển du lịch của nước ta. Tiềm năng đó thể hiện phong phú và đa dạng ở những khía cạnh sau:

Di tích lịch sử - văn hóa: Di tích lịch sử - văn hóa là công trình xây dựng, địa điểm, các di vật, cổ vật, bảo vật quốc gia thuộc công trình, địa điểm đó có giá trị văn hóa, lịch sử, hoa học. Việt Nam có rất nhiều di tích lịch sử nổi tiếng. Trong đó có tám di sản văn hóa được thế giới công nhận là Đây là một con số khá lớn không chỉ thể hiện bề dày lịch sử mà còn cả tiềm năng du lịch của Việt Nam (Dinh Thi Tuyet, Nguyen Thi Thu Thuy, Do Van Phuc, Tran Viet Hoang, 2021).

Danh thắng: Danh thắng hay danh lam thắng cảnh là cảnh quan thiên nhiên hoặc địa điểm có sự kết hợp giữa cảnh quan thiên nhiên với công trình kiến trúc có giá trị lịch sử, thẩm mỹ, khoa học. Với khí hậu và địa hình ở nước ta, danh lam thắng cảnh rất đa dạng: Việt Nam có 32 vườn quốc gia, nằm rải rác khắp mọi miền của tổ quốc. Tiêu biểu có thể kể đến như: Du Già - Cao 
nguyên đá Đồng Văn, Tam Đảo, Ba Vì,, Cúc Phương, B Phong Nha - Kẻ Bàng, Tràm Chim, Mũi Cà Mau, U Minh Hạ, U Minh Thượng, Phú Quốc, Côn Đảo,... Trong đó, có 4 nơi được công nhận là Di sản ASEAN, một được công nhận là di sản thiên nhiên thế giới (Phong Nha Kẻ Bàng). Hệ thống hang động của Việt Nam cũng rất phong phú, nằm chủ yếu ở phía bắc tổ quốc. Việt Nam đứng thứ 27 trong số 156 quốc gia có biển trên thế giới với 125 bãi tắm biển, hầu hết là các bãi tắm đẹp. Việt Nam là $1 / 12$ quốc gia có vịnh đẹp nhất thế giới là vịnh Hạ Long và vịnh Nha Trang. Hệ thống ao, hồ cùng mạng lưới sông ngòi chằng chịt với gần 2360 con sông lớn nhỏ. Có 400 nguồn suối nước nóng từ 40 - 120 độ $\mathrm{C}$. Nhiều suối có cơ sở hạ tầng khá tốt như Đam Rông, Lâm Đồng; Kim Bôi, Hòa Bình; Bình Châu, Bà Rịa Vũng Tàu,...

Văn hóa: Nói đến văn hóa, không thể không nhắc tới lịch sử phát triển lâu dài của dân tộc. Trải qua nhiều biến cố thăng trầm, văn hóa Việt Nam vừa có những nét đặc trưng, vừa có sự kết hợp của nhiều luồng văn hóa khác nhau (Q.-H. Vuong et al., 2019; Q. H. Vuong et al., 2018). Ngoài ra, nước ta có 54 dân tộc anh em cùng chung sống, mỗi dân tộc đều có những nét riêng biệt về đời sống, phong tục tập quán. Hai yếu tố này kết hợp với nhau tạo nên một sự đa dạng trong các hình thức nghệ thuật, âm nhạc. Các môn nghệ thuật sân khấu có thể kể đến như múa rối nước, chèo, tuồng, cải lương, ... Về âm nhạc thì còn phong phú hơn với chầu văn, quan họ, ca trù, nhạc cung đình,.... Sự hội nhập kinh tế thế giới và xu hướng toàn cầu hóa làm cho văn hóa nước ta mang cả nét truyền thống lẫn hiện đại. Nhắc đến văn hóa, còn có văn hóa môi trường (Khuc, 2021b, 2021a; Q.-H. Vuong, 2021; Q. H. Vuong, 2021; Q. H. Vuong et al., 2021). Đây là cụm tư tưởng được phát triển bởi Giáo sư Vương Quân Hoàng và các cộng sự. Ngành du lịch không thể tách rời văn hóa, trong đó có văn hóa môi trường. Vì thế nếu được chuyển hóa thành công và thực hành tốt cụm văn hóa môi trường này thì sẽ giúp thúc đẩy, cải thiện chất lượng dịch vụ môi trường đáng kể ở Việt Nam.

Lễ hội: Lễ hội Việt Nam là sự kiện văn hóa được tổ chức mang tính cộng đồng. "Lễ" là hệ thống những hành vi, động tác nhằm biểu hiện sự tôn kính của con người với thần linh, phản ánh những ước mơ chính đáng của con người trước cuộc sống mà bản thân họ chưa có khả năng thực hiện. "Hội” là sinh hoạt văn hóa, tôn giáo, nghệ thuật của cộng đồng, xuất phát từ nhu cầu cuộc sống.

Tuy nhiên, do ảnh hưởng của đại dịch Covid-19 du lịch Việt Nam cũng đang gặp nhiều khó khăn. Du lịch là ngành đầu tiên bị ảnh hưởng nặng nề nhưng cũng là một trong những ngành 
có khả năng sớm phục hồi. Do đó cần có những phương hướng cụ thể để khắc phục hậu quả và phát triển ngành du lịch sau Covid-19 (Thuy, Nhan, et al., 2021).

Trong tình hình thị trường du lịch nước ngoài và khách quốc tế gần như không thể khai thác được, thị trường du lịch nội địa đang trở thành chủ lực trong phục hồi của ngành du lịch Việt Nam. Do đó chiều ngày 28/9/2021, tại Hà Nội, Hiệp hội Du lịch Việt Nam tổ chức lễ phát động "Chương trình khôi phục du lịch nội địa" toàn quốc với định hướng phát triển và khắc phục hậu quả của đại dịch Covid-19. Mục tiêu của Chương trình là chuyển các hoạt động du lịch sang trạng thái "bình thường mới”, xây dựng du lịch thành một ngành kinh tế du lịch an toàn. Ngành du lịch sẽ tuân thủ nghiêm hướng dẫn của cơ quan y tế, đồng thời tổ chức các hoạt động du lịch một cách linh hoạt, thích ứng, hiệu quả với diễn biến tình hình thực tế phòng chống dịch. Yếu tố an toàn đã trở thành một yêu cầu, một nội dung bắt buộc trong mọi hoạt động du lịch. Các chuyên gia du lịch cho rằng một vấn đề cần phải thực hiện ngay từ giai đoạn này là phải tiêm vaccine phòng bệnh cho những người làm trong ngành du lịch. Phải coi những người làm trong ngành du lịch là những chiến sĩ tuyến đầu trên mặt trận kinh tế.

Do đó, cần nâng cao tỷ lệ tiêm vaccine phòng COVID-19 cho toàn dân (Nguyen et al., 2021; Van Khuc et al., 2021), đặc biệt những người lao động trong ngành du lịch, trang bị cho họ vũ khí để họ hoạt động và khách du lịch khi đến Việt Nam cũng an tâm vì được bảo vệ an toàn. Hiện đã có 1 số địa phương tiến hành tiêm vaccine cho lực lượng lao động trong ngành du lịch. Theo các chuyên gia, ngoài việc tiêm vaccine cho lực lượng lao động, các doanh nghiệp du lịch, đơn vị tạo ra sản phẩm cung ứng du lịch cần tạo ra những sản phẩm độc đáo, không đi theo lối mòn. Đặc biệt, thay vì như trước đây chỉ cạnh tranh về giá thì ngay bây giờ ngành du lịch phải thay đổi nhanh chóng và tập trung sâu sắc hơn về "chất" của sản phẩm...

Bên cạnh đó, Nhà nước cũng đã áp dụng nhiều chính sách kích cầu du lịch để hướng tới mục đích phục hồi lại ngành du lịch (La et al., 2020; Thuy, Hoang, et al., 2021). Với chủ đề "Kết nối xanh du lịch Việt Nam”, chương trình lần này nhằm đáp ứng trước tiên là khôi phục du lịch nội địa, trên cơ sở phù hợp một cách linh hoạt, thích ứng, hiệu quả với diễn biến thực tế của dịch bệnh, từng bước khôi phục du lịch trong bối cảnh sống chung với Covid-19. Các doanh nghiệp và địa phương cho rằng, việc đẩy mạnh du lịch nội địa giữa các "vùng xanh" lúc này sẽ giúp doanh nghiệp hồi sinh, nhất là trong bối cảnh hiện nay, các doanh nghiệp du lịch gần như đã kiệt quệ do ảnh hưởng bởi dịch Covid-19 dù thời gian tới hoạt động du lịch chưa thể diễn ra tự do, tự phát như trước mà cần sự kiểm soát. Tất cả các bên tham gia vào chuỗi cung ứng du 
lịch như lữ hành, lưu trú, điểm đến, ăn uống, vui chơi... đều phải tuân thủ các điều kiện "xanh" (Hương, 2017).

Thêm vào đó, Việt Nam cũng đang xem xét cho phép đón khách quốc tế trở lại trong tình hình mới. Bước đầu sẽ thí điểm ở một số địa phương và dần mở rộng theo từng giai đoạn và từng thị trường quốc tế. Việc cho phép thí điểm hộ chiếu vaccine được xem là tiền đề quan trọng để cứu nguy cho ngành Du lịch và dần thích ứng với tình hình mới hậu COVID-19 (An, 2021). Đây được xem là phương án vừa bảo đảm an toàn phòng, chống dịch vừa giúp du lịch Việt Nam từng bước vực dậy theo quá trình thích ứng với tình trạng bình thường mới. Chương trình "Khôi phục du lịch nội địa toàn quốc" cũng đã xây dựng những tiêu chí an toàn riêng đối với khách du lịch từ 18 tuổi trở lên và khách du lịch dưới 18 tuổi. Đồng thời, Chương trình đặt ra những yêu cầu đối với điểm đến du lịch, cơ sở lưu trú như: Điểm đến du lịch thuộc vùng xanh và đủ điều kiện hoạt động theo tiêu chí an toàn phòng chống dịch; phục vụ số lượng khách tại cùng một thời điểm không được quá 30-50\% công suất điểm đến (do điểm đến quy định)(Quân, 2018)...v.v...

Tóm lại, tiềm năng phát triển ngành du lịch là rất to lớn có thể đóng góp cho phát triển kinh tế đất nước trong bối cảnh hội nhập và hậu COVID-19 (Chính \& Hoàng, 2009). Việc phát huy tiềm năng nội lực và vận dụng nguồn lực bên ngoài để khơi thông tiềm năng này phụ thuộc vào nhiều yếu tố, đặc biệt là các chính sách phù hợp, sự đầu tư đúng mức, văn hóa du lịch, văn hóa môi trường, và khả năng kiểm soát dịch bệnh COVID-19.

\section{Tài liệu tham khảo}

An, L. (2021). Phát động chưong trình khôi phục du lịch nội địa toàn quốc. Báo Quốc Tế. https://baoquocte.vn/phat-dong-chuong-trinh-khoi-phuc-du-lich-noi-dia-toan-quoc160049.html\%0A

Chính, P. M., \& Hoàng, V. Q. (2009). Kinh tế Việt Nam: Thăng trầm và đột phá. Nxb Chính trị quốc gia, Hà Nội.

Dinh Thi Tuyet, Nguyen Thi Thu Thuy, Do Van Phuc, Tran Viet Hoang, N. T. T. N. (2021). Covid - 19: Du lịch bảo tàng thu hút đông đả0 lượng khách " Online ". OSF Preprints. https://doi.org/https://osf.io/gu3fj/

Giang, T. (2021). Hành động thiết thục để phục hồi ngành du lịch sau đại dịch COVID - 19. Baotintuc. https://baotintuc.vn/du-lich/hanh-dong-thiet-thuc-de-phuc-hoi-nganh-du-lichsau-dai-dich-covid19-20210815063738208.htm

Hương, T. N. T. T. (2017). Thục trạng và giải pháp phát triển ngành du lịch Việt Nam hiện 
nay. Khoa Quản Trị - Trường Đại Học Kinh Tế Kỹ Thuật Công Nghiệp).

http://www.tapchicongthuong.vn/bai-viet/thuc-trang-va-giai-phap-phat-trien-nganh-dulich-viet-nam-hien-nay-47881.htm

Khuc, Q. Van. (2021a). Environmental culture thoughts to make a better world for our nature and children. OSF Preprints. https://doi.org/10.31219/osf.io/g5zex

Khuc, Q. Van. (2021b). Khucc tower: from cultural values to practical solutions. OSF Preprints. https://doi.org/10.31219/osf.io/stbj4

La, V., Pham, T., Ho, M., Nguyen, M., Nguyen, K.-L. P., Voung, T.-T., Nguyen, T. H.-K., Tran, T., Khuc, V.-Q., Ho, M.-T., \& Vuong, Q.-H. (2020). Policy response, social media and science journalism for the sustainability of the public health system amid COVID19 outbreak: The Vietnam lessons. Sustainability, 12. https://doi.org/10.3390/su12072931

Nguyen, L. H., Hoang, M. T., Nguyen, L. D., Ninh, L. T., Nguyen, H. T. T., Nguyen, A. D., Vu, L. G., Vu, G. T., Doan, L. P., Latkin, C. A., Tran, B. X., Ho, C. S. H., \& Ho, R. C. M. (2021). Acceptance and willingness to pay for COVID-19 vaccines among pregnant women in Vietnam. Tropical Medicine and International Health, 26(10), 1303-1313. https://doi.org/10.1111/tmi.13666

Quân, M. (2018). Thực trạng du lịch hiện nay. Du Lịch Việt Nam. https://phongveminhquan.vn/thuc-trang-du-lich-viet-nam-hien-nay/\%0A

Thuy, N. T. T., Hoang, T. V., Tuyet, D. T., \& Nhan, N. T. T. (2021). Đánh giá sự hài lòng của khách du lịch đối với chất lượng dịch vụ tại resort cao cấp trong mùa dịch covid 19 ở việt nam. OSF Preprints. https://doi.org/10.31219/osf.io/ybr4v

Thuy, N. T. T., Nhan, N. T. T., Hoang, T. V., Phuc, D. Van, \& Tuyet, D. T. (2021). Tác động của dịch bệnh covid-19 đến ngành du lịch việt nam. OSF Preprints. https://doi.org/10.31219/osf.io/bjdek

Van Khuc, Q., Nguyen, T., Nguyen, T., Pham, L., Le, D. T., Ho, H. H., Truong, T. B., \& Tran, Q. K. (2021). Young adults' intentions and rationales for covid-19 vaccination participation: Evidence from a student survey in Ho chi minh city, Vietnam. Vaccines, 9(7). https://doi.org/10.3390/vaccines9070794

Vuong, Q.-H. (2021). Western monopoly of climate science is creating an eco-deficit culture. Economy, Land \& Climate Insight, 1-9.

Vuong, Q.-H., Bui, Q.-K., La, V.-P., Vuong, T.-T., Ho, M.-T., Nguyen, H.-K. T., Nguyen, H.-N., Nghiem, K.-C. P., \& Ho, M.-T. (2019). Cultural evolution in Vietnam's early 20th century: A Bayesian networks analysis of Hanoi Franco-Chinese house designs. 
Social Sciences \& Humanities Open, 1(1), 100001.

https://doi.org/10.1016/j.ssaho.2019.100001

Vuong, Q. H. (2021). The semiconducting principle of monetary and environmental values exchange. Economics and Business Letters, 10(3), 284-290.

https://doi.org/10.17811/ebl.10.3.2021.284-290

Vuong, Q. H., Bui, Q. K., La, V. P., Vuong, T. T., Nguyen, V. H. T., Ho, M. T., Nguyen, H. K. T., \& Ho, M. T. (2018). Cultural additivity: behavioural insights from the interaction of Confucianism, Buddhism and Taoism in folktales. Palgrave Communications, 4(1). https://doi.org/10.1057/s41599-018-0189-2

Vuong, Q. H., Ho, M. T., Nguyen, M. H., Pham, T. H., Vuong, T. T., Khuc, Q., Ho, H. A., \& La, V. P. (2021). On the environment-destructive probabilistic trends: A perceptual and behavioral study on video game players. Technology in Society, 65(January), 101530. https://doi.org/10.1016/j.techsoc.2021.101530 